\title{
An educational virtual lab to study a mixed gearing of wheels
}

\section{RESUMEN}

Se ha creado un Laboratorio Virtual educacional para estudiar un engranaje mixto de ruedas. Los engranajes de ruedas son comunes en aplicaciones de Ingeniería Mecánica, tal como la maquinaria industrial. Este software es ideal para la enseñanza y para el aprendizaje de las relaciones entre las ruedas de un engranaje, con tres tipos de contacto: tangencial, coaxial, y mediante una faja. El laboratorio virtual realiza simulación basada en el modelado matemático de un engranaje y permite al usuario visualizar el comportamiento de ruedas con engranajes mixtos y familiarizarse con las velocidades de rotación, numero de vueltas y otros parámetros que aparecen cuando un conjunto de ruedas constituye un mecanismo.

Palabras clave: Educación, laboratorio virtual, simulación, software, engranaje, ruedas.

An educational Virtual Lab to study a

Mixed Gearing of WheEls

\section{ABSTRACT}

An educational Virtual Lab dealing with a mixed gearing of wheels has been created. Gears of wheels are common in Mechanical Engineering applications, like industrial machinery. This Virtual Lab is ideal when teaching and/or learning the relationship between geared wheels having three types of contact: tangent, coaxial, and by a belt. The virtual lab performs simulation based on the mathematical modeling of the gearing and allows the user to visualize the behavior of a mixed gearing of wheels and to get acquainted with the rotation speeds, number of turns and other parameters that appear when a set of wheels are geared

Keywords: Education, virtual lab, simulation, software gearing, wheels gear.

\section{INTRODUCTION}

"Seeing is believing", teachers and students know that this is especially true at the classroom, where usually not all but many students are lost and puzzled at the jungle of mathematical equations common at engineering courses.

Usually when dealing at the classroom with rotating wheels in contact, the teacher makes a drawing on the blackboard or displays a pre-designed sketch, and making use of the circular motion equations from physics, the mathematical relationships between the wheels are deduced. In this way, magnitudes like rotation angular speed, peripheral tangent velocity, number of turns, linear displacement, etc, are calculated. Starting from this information the student has to imagine the motion of the wheels. Maybe the teacher might make another drawing and show an additional case. A class session like the just described is very arid, because even though the teacher made his/her best effort, the student learned only the equations and how to operate with them, but the phenomenon itself remains untouched because nobody can see it.

In circumstances like the above described it would be very useful having simulation software based on mathematical modeling which shows the true dynamics of the gearing. This software would be much better if it allows parameter changing and if it is enabled to visualize the parameter changes made by the user.

The just created Virtual Lab being reported in this article is very useful at the above described circumstances, because it gives opportunity to the user to visualize the geared wheels, permitting him/her to change parameters like the radiuses of the wheels and their angular speed, showing on screen (visualizing) a mathmodel based animation reflecting the changes, and reporting the corresponding experimental data.

In the development of the geared wheels Virtual lab, the following computer programming techniques have been used: Object Oriented Programming, Modular and Structured Programming, Computer Graphics, and Double Buffering ${ }^{[1-5]}$. 


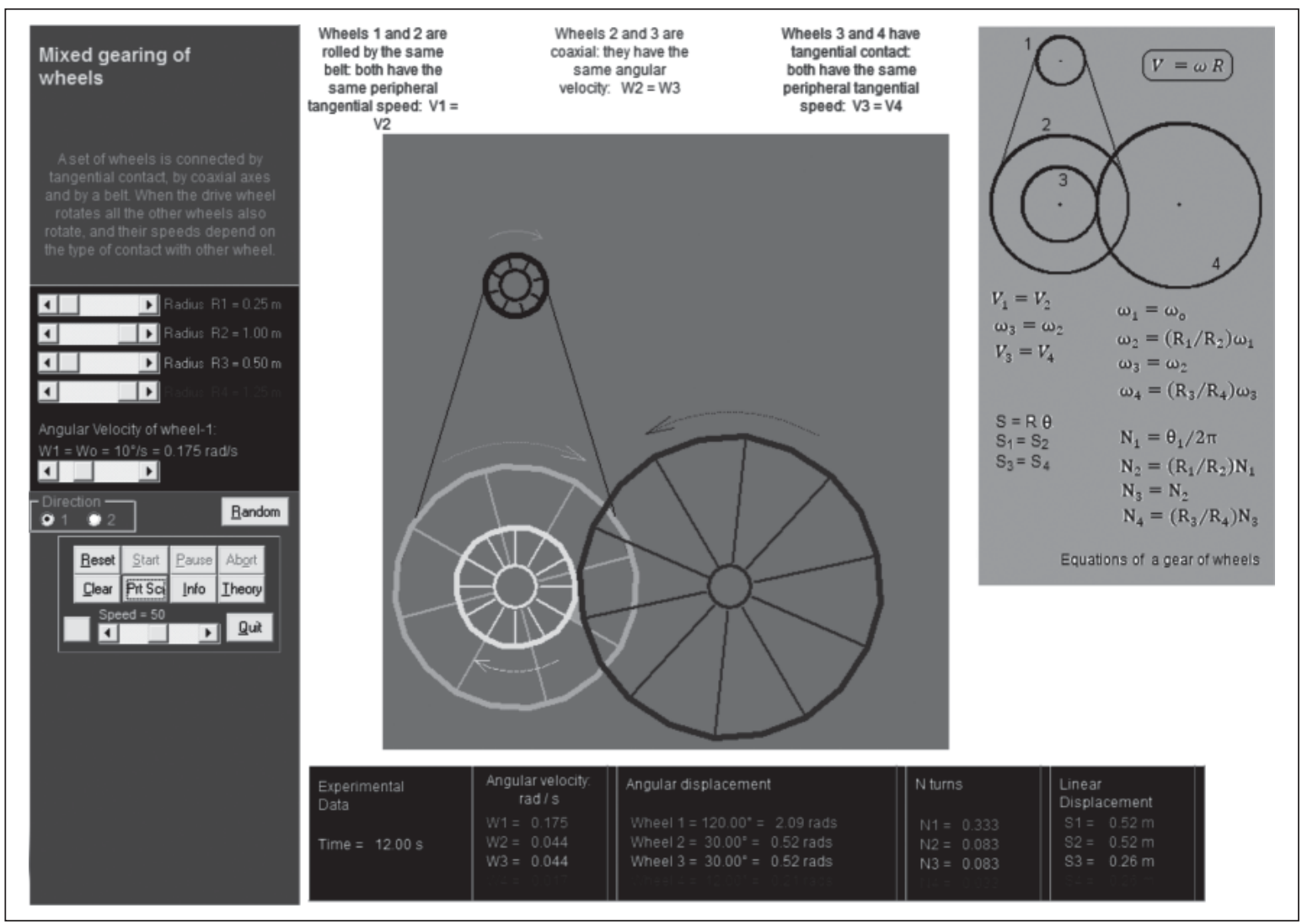

Fig. 1. Screenshot of the Virtual Lab dealing with a mixed gearing of wheels.

\section{DESCRIPTION OF THE VIRTUAL LAB}

Fig. 1 shows a screenshot of the module dealing with a mixed gearing of wheels. As it can be seen the geared wheels virtual lab puts on display four wheels, one of them being the main wheel, this is, the drive wheel, the one that would be connected to a motor or maybe the motor itself, in real life. The other three wheels rotate just because they are somehow in contact with the main wheel.

Of the four wheels (see fig. 2), two are connected by a belt, two are coaxial, and two have tangential contact. The user can change the radiuses of the four wheels and he/she can also change the angular speed of the main wheel (wheel 1 in Fig. 2 ). Depending on the type of contact the wheels acquire the corresponding angular speed, rotate a number of turns, etc.
The Virtual Lab shows the wheels in different colors so that visualization is easy, the reported data corresponding to each wheel is displayed in the same color of the wheel.

Additional features of the software include the random setting of initial data, the freezing of time and the capture and printing of screen shots. Furthermore an abridged theory is shown on the screen so that the user can give a glance to the theory and verify it while the gear dynamics takes place.

With the random setting of initial data the radiuses of the four wheels as well as the angular velocity of the main (drive) wheel are fixed at random, in this way, many different combinations of wheels and initial driving velocities can be visualized and assessed quickly, which is of great utility when the intention is to make many experiments in a short period of time. 


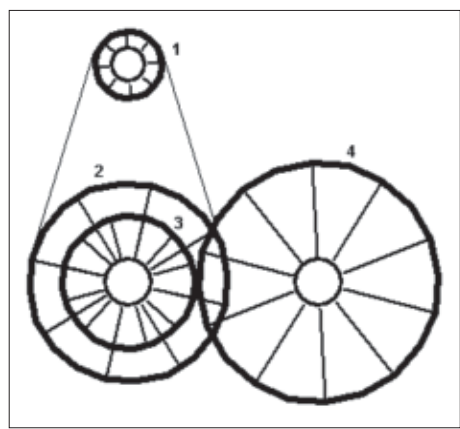

Fig 2. Wheel number 1 is the drive wheel, the one leading the motion of the others and the one connected to the axis of a motor. Wheels 1 and 2 are connected by a belt. Wheels 2 and 3 are coaxial. Wheels 3 and 4 are tangent.

Since the developed software reports the results of computations with the data introduced by the user, it may also be used as a quick source of questions for exams and tests to be posed to students. This feature may also be useful for students who want to learn more on gearings of wheels, because they may make experimentation with their own data and check their mathematical results previously made.

Fig. 3 shows some randomly generated configurations of the four geared wheels, the random option randomly sets the radiuses of the four geared wheels and the angular speed of the driving wheel (the one at the top of each configuration), While the software executes showing the rotating wheels on screen, it numerically reports their number of turns, their angular and linear displacements, and the elapsed time.

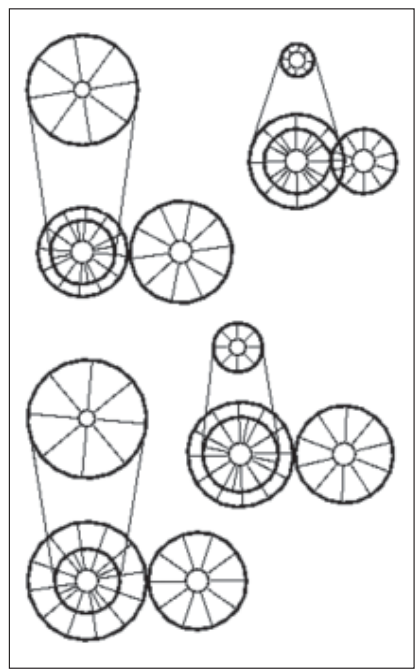

Fig 3. Some different randomly generated configurations of four geared wheels.

\section{EQUATIONS OF A GEAR OF WHEELS}

The simulation executed by the Virtual Lab being reported in this paper is based on the equations governing the motion of a gear of wheels, which are dealt with by the physics of uniform circular motion ${ }^{[6]}$ and state the following rules

- Wheels rolled by the same belt, have the same peripheral tangential speed, this is the case of wheels 1 and 2 (Figs. 2 an 4)

- Coaxial wheels have the same angular velocity (see wheels 2 and 3).

- Wheels having tangential contact have the same peripheral tangential speed (see wheels 3 and $4)$.

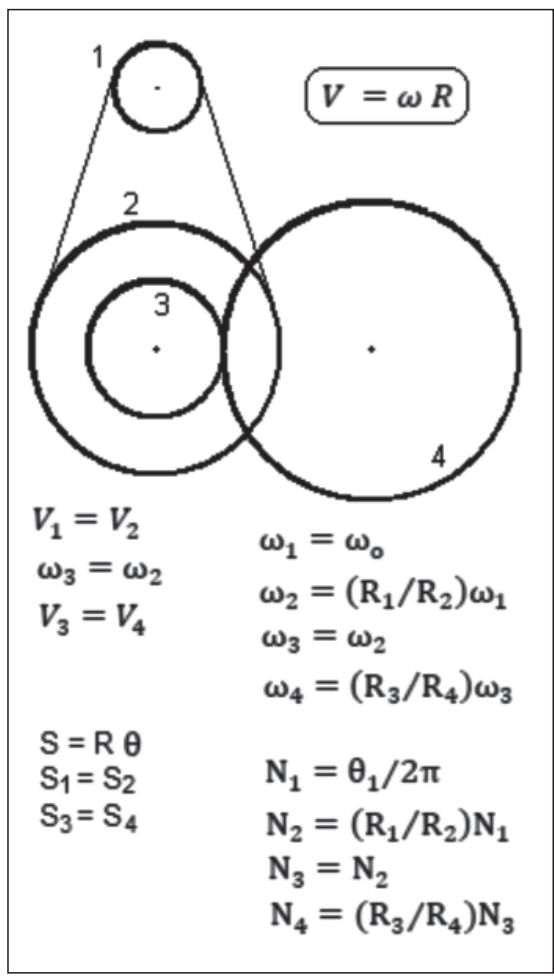

Fig. 4. shows the equations of a gear of four wheels. In general, $\mathrm{V}$ is the peripheral tangent velocity of a point at the edge of a wheel of radius $R$, rotating with angular velocity $\omega$, and completing $\mathrm{N}$ turns in a given time, thus displacing a distance $S$ and an angle $\Theta$.

\section{CONCLUSION}

An educational Virtual Lab dealing with a mixed gearing of four wheels has been developed; this software is useful at both teaching and learning, it 
allows visualization of the rotating wheels while the corresponding equations of motion are evaluated in real time. The developed software is fully friendly and includes a number of special features which improve the quality of learning and teaching with it. The software described in this paper has been included as a new module in the PVL ${ }^{[7]}$.

\section{REFERENCES}

[1] Object-oriented programming; An Introduction. Greg Voss, Mc Graw Hill, 1994

[2] Software testing techniques, Boris Beizer, Van Nostrand Reinhold, 1983

[3] Borland C++ Handbook, Pappas \& Murray, Mc Graw Hill, 1994

[4] Computer Graphics, Foley-van Dam-FeinerHughes, Addison Wesley, 1996

[5] Animation Techniques in Win32, Niget Thompson, 1995

[6] Fundamental University Physics, Alonso \& Finn, Addison-Wesley
[7] Physics Virtual Lab. PVL, Javier Montenegro Joo, VirtualDynamics , 2010

\section{The Author}

Javier Montenegro Joo (JMJ) simultaneously studied both, Physics and Computation (Computer Science) at San Marcos University (Peru), graduating as a Bachelor in Physics. He worked as scientificsystems analyst and computer programmer at the Peruvian Institute of Geophysics. JMJ obtained a Master of Science degree with a major in Computational \& Simulational Physics (The Ohio University, USA), and a Doutoral Qualificação in Cybernetic Vision (Artificial Intelligence) (University of São Paulo, São Carlos, Brazil). JMJ is founding director of VirtualDynamics Science \& Engineering Virtual Labs., he is also an Associate Member of the ICTP (Italy). Virtual Labs developed by JMJ are successfully commercialized all over the world via internet. Besides developing software for technical and scientific applications, JMJ teaches Physics and some computer related courses at the university. 